\title{
Impact of endoluminal stenting for aortic surgery ${ }^{\text {th }}$
}

\author{
Ludwig K. von Segesser*, Bettina Marty, Piergiorgio Tozzi, Patrick Ruchat
}

Department of Cardio-vascular Surgery, Centre Hospitalier Universitaire Vaudois, Lausanne, Switzerland

\begin{abstract}
Summary
The advent of stents has profoundly changed percutaneous transluminal coronary angioplasty (PTCA), peripheral transluminal artery angioplasty (PTA), and treatment strategies of numerous other problems. Similar developments can be observed for stent applications in peripheral vascular lesions, cerebro-vascular disease, and many other fields. With the advent of covered stent-grafts, aneurysm surgery, has been put up for competitive treatment approaches. Such new approaches are perceived as less invasive, and draw significant attention. Endovsacular aneurysm repair (EVAR) is here to stay. In addition new developments are coming in many ways and stent derived devices can by now be found everywhere in the cardio-vascular system. This includes stenosed vessels, aneurysmal vessels, diseased valves, all sorts of congenital heart defects, and even cardiopulmonary bypass. The key technologies and know-how for EVAR are available or can be made available in most cardio-vascular surgical units. Special interest in this field (clinical and/or experimental) can enhance recruitment of patients. The opposite is also true...
\end{abstract}

(C) 2004 Published by Elsevier B.v.

Keywords: EVAR; Endovascular aneurysm repair; Covered stents; Valved stents; Surgery

\section{Impact in the past}

The advent of stents has profoundly changed percutaneous transluminal coronary angioplasty (PTCA), peripheral transluminal artery angioplasty (PTA), and treatment strategies of numerous other problems.

As a matter of fact, stent-based treatments of coronary artery stenoses are by now in many countries far more frequent than the formerly so successful coronary artery bypass graft (CABG) procedures. This development has occurred despite the fact, that traditional left internal thoracic artery to the left anterior descending coronary artery implants have the best long-term patency, and that coronary artery bypass graft (CABG) procedures provide superior long-term outcome with less adverse events. In addition, off-pump coronary artery bypass (OPCAB) allowing for elimination of pump related events, did not substantially change the increased use of the even lesser invasive stentbased treatments strategies.

Similar developments can be observed for stent applications in peripheral vascular lesions, cerebro-vascular lesions, tracheo-bronchial lesions, hepato-biliary and

\footnotetext{
Presented at the EACTS Symposium for the Future of Cardiac Surgery, Frankfurt, Germany, July 1-2, 2004.

*Corresponding author. Tel.: +4121 3142280; fax: +41213142279.

E-mail address: ludwig.von-segesser@chuv.hospvd.ch (L.K. von Segesser).

URL: http://www.cardiovasc.net.
}

pancreatic problems, as well as genito-urinary affections. In addition, a number of stent-derived treatment modalities are proposed, and used in increasing proportions for closure of the patent ductus arteriosus, foramen ovale, atrial septal defects, ventricular septal defects, etc. Despite non-negligible complication rates and incomplete treatments, percutaneous procedures are overall far more popular among both, doctors and patients.

With the advent of covered stent-grafts, yet another field of cardio-vascular surgery, namely aneurysm surgery, has been put up for competitive treatment approaches, and once again, the new approach is perceived as less invasive, and draws significant attention.

\section{Impact in general}

Thoracic aortic aneurysm and thoracic aortic dissection repair has traditionally been an almost exclusive domain of cardiac and cardio-vascular surgery. However, this activity based on open surgery with and without adjuncts (cardiopulmonary bypass, deep hypothermic circulatory arrest, left heart bypass, selective perfusion, etc.) is more and more under attack by (non-)surgical experts promoting endovascular aneurysm repair based on covered stent-grafts.

There are number of reasons for this development, but some of them are difficult to understand. The theoretical and practical know-how for EndoVascular Aneurysm Repair (EVAR) by the means of covered stent-grafts was and is 
available in many cardio-vascular surgical units, where the daily routines include implantation of intra-aortic balloons, percutaneous cannulation, pacemaker and defibrillator implantation with epicardial and trans-venous leads, insertion of caval filters, per-procedural angiography, etc. These techniques require not only intimate knowledge of the material necessary for the mentioned procedures but also regular practice with the Seldinger catheter technique, fluoroscopy, ultrasound, and other imaging equipment. However, most surgeons have not been among the early adopters of endo-vascular aneurysm repair. Hence, many specialists from other fields with helpful diagnostic and/or therapeutic skills, like angiologists, cardiologists, neurologists, radiologists, and vascular surgeons, got interested in EVAR before the cardio-vascular surgeons, and, as a result, increased competition between procedures first, and for patients, second, occurred.

\section{Impact in Lausanne}

Out of the 30,000 patients registered in our database, 985 cases suffered from abdominal aortic aneurysms (3.2\%), 466 for ascending aortic aneurysms (1.5\%), 219 for type A aortic dissections $(0.7 \%), 197$ for descending thoracic and thoracoabdominal aortic aneurysms $(0.6 \%), 110$ for peripheral arterial aneurysms $(0.4 \%)$, and 56 for type B aortic dissections $(0.2 \%)$ (all aneurismal lesions $=6.6 \%$ of our case load). Over the last 10 years $(13,182$ cases), abdominal aortic aneurysms accounted for 442 cases (3.4\%), ascending aortic aneurysms for 286 (2.2\%), type A aortic dissections for 135 (1.0\%), descending thoracic and thoraco-abdominal aortic aneurysms for $132(1.0 \%)$, peripheral arterial aneurysms for $85(0.6 \%)$, and type B aortic dissections for 41 (0.3\%) (all aneurysms $=8.5 \%)$. Throughout the 10 -year observation period, EVAR was used in 66/132 descending thoracic and thoraco-abdominal aortic aneurysms $(50 \%)$, whereas the corresponding numbers are $149 / 442$ for the abdominal aorta (34\%). At the beginning of this study period, in 1994, EVAR was not available, whereas nowadays it is used almost exclusively for early and late repair of traumatic aortic ruptures, $50 \%$ of descending thoracic aortic aneurysms, and $40 \%$ of abdominal aortic aneurysms. The aneurismal lesions (all) account by now $14.5 \%$ of our caseload as compared to $6.6 \%$ over the entire period studied (see above).

Interestingly enough, EVAR procedures at the Department of Cardio-vascular Surgery, CHUV in Lausanne are entirely performed by the surgical team. As a matter of fact, we rely only so far on pre-procedural imaging as it is necessary for the establishment of the diagnosis, and preliminary assessment of feasibility. A mobile cart with the most frequently used guide-wires, introducers, catheters, and other ancillary equipment (Fig. 1) can be readily moved to the specific operating theatre together with the machine for intravascular ultrasound (IVUS), and the C-arm for fluoroscopy. Perprocedural road-mapping is based on IVUS and fluoroscopy, which are used for target site identification, neck quality assessment, and all necessary measurements for device selection [1]. Straight thoracic aortic, straight abdominal aortic, tapered aorto-iliac, and bifurcated aorto-iliac

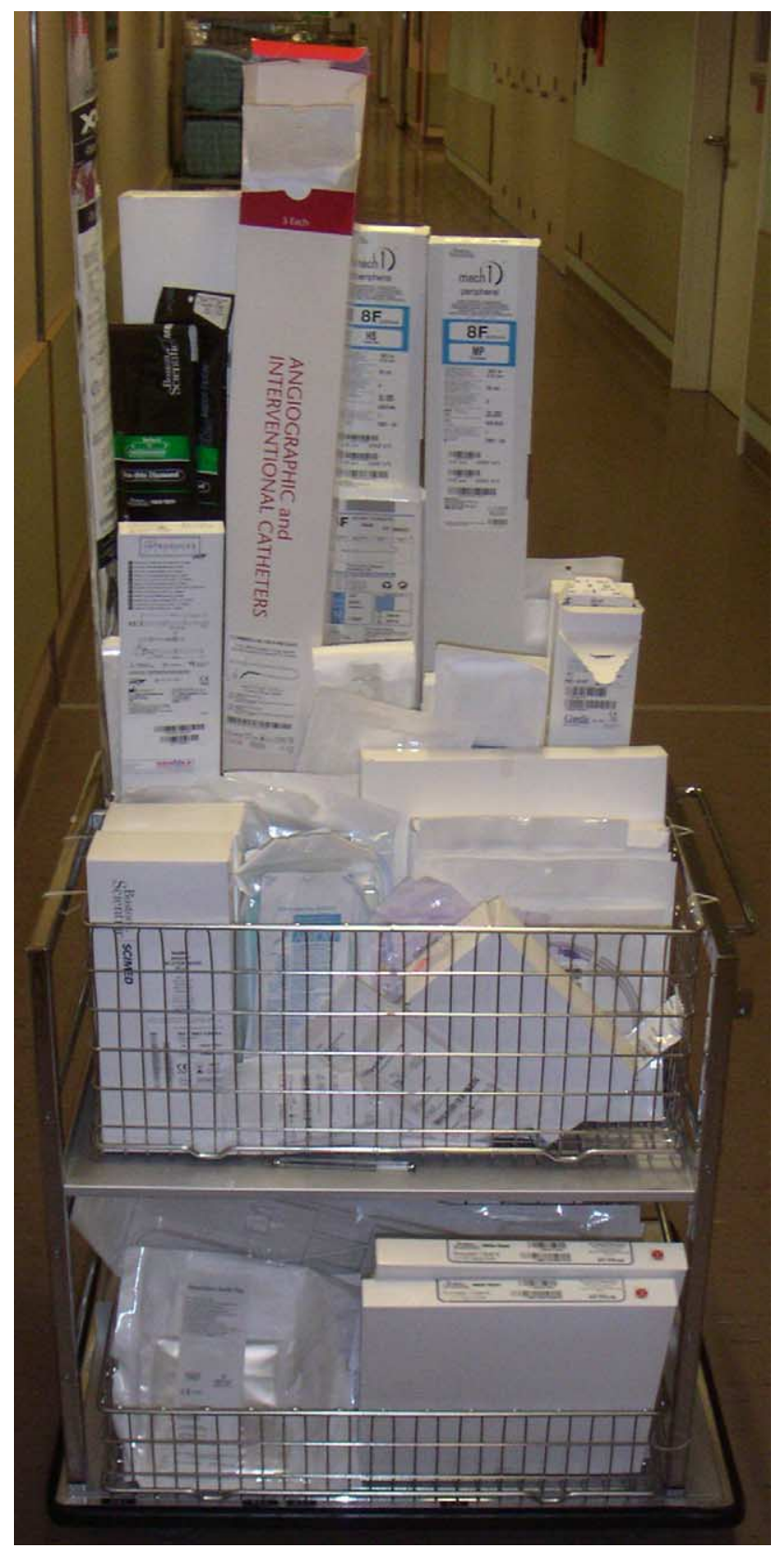

Fig. 1. Mobile cart with the most frequently used guide-wires, introducers, catheters, and other ancillary equipment for EVAR in the operating theatre.

covered stent-grafts are selected out of our in-house stock (Fig. 2) holding most current device configurations in various dimensions as well as the corresponding extensions, plugs, etc. As a result, emergency and semi-elective endo-vascular procedures can be realized at any time, and in our hands only very few custom made devices are nowadays necessary for established EVAR indications. In house developments enhancing indications for EVAR include in situ introducer sheath dilatation [2] for patients with complex aortic access, as well as partial inflow occlusion [3] for blood pressure (flow) control during device positioning and deployment. Finally, we rely primarily on ultrasonic imaging for early quality assessment. The techniques described have been made available to remote teams through tele-medecine 


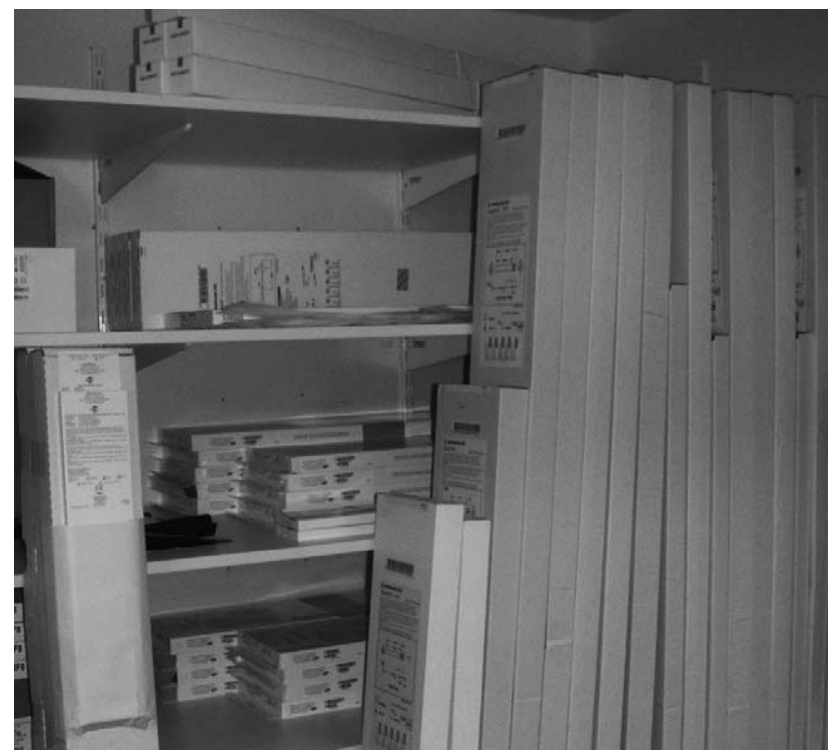

Fig. 2. In-house stock holding most current device configurations for abdominal (bifurcated grafts (body diameter 23-32 mm) and limbs are horizontal), aorto-mono-iliac grafts (vertical on the left) and thoracic (vertical on the right: $24-46 \mathrm{~mm}$ in diameter with various lengths) EVAR in various dimensions as well as the corresponding extensions, plugs, etc.

and tele-monitoring [4], as well as through dedicated handson workshop modules (www.heartlab.org).

\section{Impact for the future}

The most limiting factor in EVAR is at this time the presence of significant aortic branches within the aneurysm neck or within the aneurysm. Hence, the development of fenestrated covered stent-grafts allowing for covering aortic side orifices without compromising side branch blood flow [5] as well as the design of covered stent-grafts with modular side branches [6] address both these issues and have the potential to push the current limits significantly further as endo-vascular repair of juxtarenal abdominal aortic aneurysms, abdominal aortic aneurysms with suprarenal extension, thoraco-abdominal aneurysms as well as aortic arch aneurysms may eventually be cured with such devices. An interesting development based on the knowledge gathered from covered stent-grafts, is the already available venous smart canula for less invasive cardio-pulmonary bypass. The latter can be inserted over a guide wire through a peripheral (femoral) vein into the vena cava, and expanded in situ, thus doubling its cross-sectional area, an effect that allows to achieve full venous flow based on gravity drainage alone [7].

However, the most spectacular steps forward, were certainly made in the field of prosthetic heart valve replacement, where the advent of valved stents could have a huge impact on the daily practice of cardio-vascular surgery. For the time being, most non-surgical players in this field focus on percutaneous access $[8,9]$, which automatically limits the potential candidates for such procedures due to the limited access vessel diameter and the navigation problems due tortuous and/or stenosed vessels. However, despite these difficulties, there have been several reports on clinical applications of valved stents in pulmonary [10] as well as aortic position [11]. For the latter application, there still remain a number of issues including the fate of the coronary arteries [12], and the question whether calcified valve leaflets should be removed or not. It may also turn out, that the percutaneous route from the groin or neck is not the best access to the heart, and that a direct (surgical [13]) mini-invasive approach for antegrade implantation of valved stents is superior $[14,15]$.

\section{Conclusions}

EVAR is here to stay. New developments are coming in many ways and stent derived devices can by now be found everywhere in the cardio-vascular system. This includes stenosed vessels, aneurysmal vessels, diseased valves, all sorts of congenital heart defects, and even cardiopulmonary bypass. Key technology for EVAR is available or can be made available in most cardio-vascular surgical units. Special interest in this field (clinical and/or experimental) can enhance recruitment of patients. The opposite is also true...

\section{References}

[1] von Segesser LK, Marty B, Ruchat P, Bogen M, Gallino A. Routine use of intravascular ultrasound for endovascular aneurysm repair: angiography is not necessary. Eur Vasc Endovasc Surg 2002;23:537-42.

[2] von Segessser LK, Marty B, Tozzi P, Corno A. In situ introducer sheath dilatation for complex aortic access. Eur J Cardiothorac Surg 2002;22: 316-8.

[3] Marty B, Morales CC, Tozzi P, Ruchat P, Chassot PG, von Segesser LK. Partial inflow occlusion facilitates accurate deployment of thoracic aortic endografts. J Endovasc Ther 2004;11:175-9.

[4] Bonvini RF, Coaduro L, Menafoglio A, Calanca L, von Segesser LK, Gallino A. Telemedicine for cardiac surgery candidates. Eur J Cardiothorac Surg 2002;22:377-80.

[5] Verhoeven ELG, Prins TR, Tielliu IFJ, Van Dungen JJAM, Zeebregts CJAM, Hulsebos RG, Van Andringa de Kempenaer MG, Oudkerk M, Van Schilfgaarde R. Treatment of short-necked infrarenal aortic aneurysms with fenestrated stent-grafts: short term results. Eur J Vasc Endovasc Surg 2004;27:453-567.

[6] Vos AWF, Linsen MAM, Wisselink W, Rauwerda JA. Endovascular grafting of complex aortic aneurysms with a modular side branch stent graft system in a porcine model. Eur J Vasc Endovasc Surg 2004;27:492-7.

[7] Mueller X, Mallbiabarrena I, Mucciolo G, von Segesser LK. Optimized venous return with a self-expanding cannula: from computational fluid dynamics to clinical application. Interact Cardiovasc Thorac Surg 2002;1: 23-7.

[8] Lutter G, Kuklinski D, Berg G, von Samson P, Martin J, Handke M, Uhrmeister P, Beyersdorf F. Percutaneous aortic valve replacement: an experimental study. I. Studies on implantation. J Thorac Cardiovasc Surg 2002;123:768-76.

[9] Corno F, Zhou J, Tozzi P, von Segesser LK. Off-bypass implantation of a self-expandable valved stent between inferior vena cava and right atrium. Interact Cardiovasc Thorac Surg 2003;2:166-9.

[10] Boenhoffer P, Boudjemline Y, Saliba Z, Merckx J, Aggoun Y, Bonnet D, Acar P, le Bidois J, Sidi D, Kachaner J. Percutaneous valve replacement of pulmonary valve in a right-ventricle to pulmonary artery prosthetic conduit with valve dysfunction. Lancet 2000;356:1403-5.

[11] Cribier A, Eltchaninoff $H$, Bash A, Borenstein N, Tron C, Bauer F, Derumeaux G, Anselme F, Laborde F, Leon MB. Percutaneous transcatheter implantation of an aortic valve prosthesis for calcific aortic stenosis: first human case description. Circulation 2002;106: 3006-8. 
[12] Huber C, Tozzi P, Corno AF, Marty B, Ruchat P, Gersbach P, Nasratulla M, von Segesser LK. Do valved stents compromise coronary flow? Eur J Cardiothorac Surg 2004;25:754-9.

[13] Zhou JQ, Corno AF, Huber CH, von Segesser LK. Self-expandable valved stent of large size: off-bypass implantation in pulmonary position. Eur J Cardiothorac Surg 2003;24:212-6.

[14] von Segesser LK. Direct percutaneous valve replacement. Eur J Cardiothorac Surg 2004;26:873-4.

[15] Pawelec-Wojtalik M, Anatosik P, Wasiatycz G, Wojtalik M. Use of muscular VSD Amplatzer occluder for closing right ventricular free wall perforation after hybrid procedure. Eur J Cardiothorac Surg 2004;26: 1044-6.

\section{Appendix. Conference discussion}

Dr C. Mestres (Barcelona, Spain): You know, Ludwig (Ludwig von Segesser), when we think about it, I think the key point is that the surgeon has to lead the path, and we may agree in collaborating with the radiologist, or whoever, but the surgeon should be the leader.

Keith Dawkins was telling something current with this, they don't have beds, and this is true, it should hold true, because it is a very important point, which is whoever does an interventional procedure, in many cases, as you know, that especially interventional guys have gone that way, or radiologists, they go that way, one thing is to work and dilate angiograms, another thing is to work and dilate patients, and this is the key point.

This is why the surgeon must always be the leader.

I think we will see many problems in the future, because the problem to me is that many of the people involved in endovascular work do not know anything about anatomy, physiology, medicine and surgery of the systems.

Craig Miller was very clear at the Lisbon meeting saying that the problem is not that we invent a new technology or develop a new technology like endovascular stenting, it is that who will get the complications that are going to be in the future. We know almost everything about conventional prostheses, especially those that still do vascular surgery. They become infected, they may have complications in the early, mid, and long-term run, $5,10,15,20$ years after that, and the problem is, who is going to take those cases? I think it is the surgeon. So we are learning. Probably endovascular work is going to be very good in the thoracic sector because of morbidity. This does not really hold true so far for the abdominal aorta, because we are still learning and the experiences from the Eurostar registry, they go that way.

So I think the point is that the surgeon must always be the leader. That is my opinion.

Dr M. Turina (Zurich, Switzerland): I can only support Ludwig's statement, the surgeon should stay in control. There is no more embarrassing field than the ruptured aortic aneurysm, both abdominal and thoracic, and if you can reduce the mortality of your ruptured abdominal aneurysm below $30 \%$, you are a very good surgeon. Having a system where in the emergency room we run the $\mathrm{CT}$ and immediately perform endoaortic prosthesis, we have reduced the mortality in the last two years to less than $5 \%$ in ruptured abdominal aortic aneurysms, and the same holds true for thoracic aneurysms, which are really a challenging task. You yourself, Ludwig, published once a paper about our ruptured thoracic aneurysms, with substantial mortality.

But I can only make a plea, that endoaortic prostheses is a surgeon's field, and should stay so. Surgeons do not only have the beds, the intensive care, but also can treat the possible complications. The problems might arise with internal iliac artery ischemia, or with left subclavian artery ischemia, which will need carotid to subclavian bypass; and the patients must be closely followed after the EAP. The radiologists do not have this possibilities, which is reflected in their publications: very little is known about the patients a year later.

Dr J. Revuelta (Santander, Spain): I think with Ludwig's experience we can learn an important lesson concerning the leadership, as Carlos Mestres said. Why we or Ludwig are the leaders in endovascular stenting, we are the leader in Santander in endovascular stenting, is only one reason, because we have the patients. We have the patients in our out-patient clinics; they are our patients. So why do we have a problem on the cardiac side? We have a problem on the cardiac side in Santander. Why they are eating the cake, pacemaker, defibrillator, coronary surgery, congenital, ASD, you know, all of this, and now valves, because they have the patients.
So as has been explained this morning, our specialty is changing drastically. And why be afraid about changing, why be afraid about new revolutions? Probably we started as thoracic surgeons, and then we joined our forces, and now we are quite separated as cardiac. In Spain only a few centers are real cardiovascular, only a few, and we will disappear too.

So probably, in my opinion, we need to be where the patients are. So we must join the cardiologists. And why not? Try to invent a new specialty, cardiovascular specialty, in the future. Is there any possibility for that? Not from our side. We tried to convince cardiology that they need to learn how to put a patient on cardiopulmonary bypass, repair the valve. So as soon as the future people start learning how to put patients on cardiopulmonary bypass during surgery, we are inventing a new specialty, cardiovascular specialty, and this way we have the patients again. Otherwise it will be, in my opinion, very difficult, and we are just waiting for other people eating our cake.

Dr F. Mohr (Leipzig, Germany): Even if I contradict Ludwig a little bit, I think we have to acknowledge that the cardiologists at least are more experienced in catheterization and they understand angiography, at least at the moment, much better than our specialty.

I do not believe that it is a question of who is in command. I think we have to form a specialized group like just has been said by Dr Revuelta. A cardiologist/endosurgeon has to specialize in such treatments, and obviously the patient together, the two together, both of them have to understand the endovascular treatment. Otherwise it may well happen that the angiologists or peripheral angiologists can just do it by themselves. They see their own patients, they don't send them to surgery at all, and there will be a complete percutaneous application possible without the need for exposure of the femoral arteries or something like that. I think we just have to overcome the thinking that the surgery has to be done by the cardiac surgeon. I think we just have to form a team out of two members or three members who really focus on aneurysms, and the same is true for mitral valves, and put these people together to get excellent results. Otherwise if you let me try the catheter technique right now, I have to restudy the whole procedure, and most of us are not ready to do that.

Dr von Segesser: I do not agree at all. I think the trick is exactly that you don't need angiography, and if you don't need angiography, you don't need somebody to do the angiography. You can do these procedures without angiography. We have done now hundreds without.

$\operatorname{Dr}$ R. Bolton (Greenwood, SC, USA): I am hearing the same theme that we had in the last talk, and that is an 'us-them' idea, and I don't see that at all. I think that the point of this is looking to the future, and I agree that doing that is going to take a team approach. I do not care to see all the patients the cardiologist sees, and I think if we take one little train of endovascular stenting or maybe it is angiography, or whatever it happens to be, we are narrowing ourselves and our practice into a very small practice.

I believe personally that we need to be a team approach, and that is that we develop service lines and we work as a team. I don't want to screen 100 patients to operate on one. I don't want to be doing all the other things. And I do still like to do general thoracic surgery in addition to cardiac surgery. But I think as we look to the future, we can't put ourselves in a niche. We have to work at things as a team and we have to change our process. I was brought up, as most of us were, in a surgery-oriented service line, and then our medical colleagues in medicine. It has always been surgery versus medicine, and I think we have to get past that.

We are in this room, for the predominant part, treating a particular disease process from start to finish, and it should include everything in between, and the technologies will be developed. It would be ridiculous to think that a cardiologist or any other person was going to do endovascular stenting without some sort of backup, at least initially, because there will be complications. There are complications whether it is done robotically or in the cath lab. And what I see after my career is it is going to be a biological engineered specialty where you get a shot in the arm and the calcium deposits go away. That is so far beyond me, but it is not beyond our industry colleagues that are looking at that today.

So those are my comments, for what it is worth, but I think we are kind of barking up the wrong tree to say that we are going to solve the problems by thinking, at least in the United States, I honestly don't see the cardiologists going away and me taking over their job, and neither do I want to, but I can work as a team, and we can do things very well together and complement one another rather than being at odds.

$\operatorname{Dr}$ A. Haverich (Hannover, Germany): For this discussion there is one issue missing, and that is, the patient. I think we should put the patient first in our thinking and talk about what kind of structure would help the patient to 
get the best treatment modality that is available. It will definitely be a team approach, because we can learn something from the cardiologists in terms of bidimensional and black and white type of thinking, and vice versa, I think the cardiologists may be able to learn something from us like three-dimensional thinking and also thinking in colors, which may be important.

Now, Keith Dawkins and myself have been knowing each other for the last 20 years, we were fellows together at Stanford, and we had some very good discussions in the past. I can tell you, Keith, I think it is going to be much easier to teach a surgeon to do a coronary angiography rather than to teach a cardiologist to think three-dimensionally for aortic valve repair on an interventional base.

Again, I think it must be a team approach and this is the way we should structure that for the future. If we don't work it as a team approach, the following scenario will be present, like with PTCA and coronary stents: the definition of success will vanish. In aortic stenosis, the gradient will drop from 80 to 40 , and this will be defined as a success. If there is a leak in that interventionally placed aortic valve, that will be tolerated, whereas at the present time no leaks would be tolerated. And the patient selection will be such that in multicenter trials, the interventional approach will be superior to the surgical approach, just by selection of the patients. This is the scenario that will happen, so we have to put our fingers into that scenario.

But again, I would see the best way to do it for the patient and get into a team approach, and I have no objections if the surgeon would be leading that team.

Dr T. Aberg (Umea, Sweden): The team approach is organizationally manifest in the new development of heart centers where all the specialties work together, and there have been some spectacular successes with the organizational forum of the heart center.

Dr D. Cosgrove (Cleveland, $\mathrm{OH}, \mathrm{USA}$ ): I think that you are going to realize in the United States that the patients who have cardiac disease are controlled by the cardiologists, and if the cardiologists are given the tools, the cardiologists are going to use them, and I think basically we have to decide, are we going to be surgeons or are we going to be cardiologists, and if you want to be a catheter-based therapist, I think you might be better off following that specialty which is designed to train.

Now, I don't think that applies to aortic disease. In aortic disease surgeons control the patients and the surgeons have the decision whether they are going to operate on them or they are going to use stenting or endovascular techniques, and I think that is perfectly appropriate, but it is certainly totally different for cardiac disease in the United States. We don't have the specialty training, we don't have the licensure to go into the cath lab, we don't control the cath lab, we don't control the patient, and to think that we are going to change that is, in the United States anyhow, a fallacy. And more importantly, we have to decide how we want to spend our days: do we want to wear a mask or do we want to wear lead?

Mr T. Treasure (London, UK): I am much more interested in the team focusing on what is best for the patient. In the case of thoracic aortic disease and the use of stents, the work is being done in a team: vascular radiology cardiothoracic and vascular surgeons who have (in our case) a sort of arbitrary division at the diaphragm.

Lung cancer similarly. The surgeon has a role in diagnosis, in staging, and in resection. Because resection is only appropriate for a minority of lung cancer, management is inevitably a team approach. All the cases are discussed, and the best combination of diagnostic staging and treatment strategies is put together for that patient. No camps. No sides.

Cardiac surgery used to be like that when I started. We discussed every case, valves or coronaries, and we put together a plan whether for continued monitoring or that it was time for surgery, and we did that the whole time. That is one of the things which I missed more and more in the last, say, five years of doing cardiac surgery. I have regained in my present work in the last four years in thoracic surgery. I am back with a team, and it is a more enjoyable and better way to work. 